\title{
Fabrication of Transparent Composites from Pinaceae Wood Packaging Residues
}

\author{
Nguyen Hoc Thang ${ }^{1 *}$, Nguyen Thuc Boi Huyen \\ ${ }^{1}$ Department of Materials Technology, Faculty of Chemical Technology, Ho Chi Minh City University of Food Industry, 700000 Ho \\ Chi Minh City, 140 Le Trong Tan Street, Vietnam \\ * Corresponding author, e-mail: thangnh@hufi.edu.vn
}

Received: 09 February 2021, Accepted: 08 June 2021, Published online: 05 October 2021

\begin{abstract}
In the $21^{\text {st }}$ century, mankind has witnessed the rapidly development of all industries with a lot of new products in a variety of types and designs. However, this development has been also causing many problems with the society and the ecological environment such as a wasteful excess of products, exhaustive exploitation of natural resources, indiscriminate deforestation, and waste pollution affecting the living environment, ecosystem, and human health. Many organizations and governments are calling for environmental protection, limit waste emissions, and find good solutions to use the recycled materials as raw materials in production plants. This study would like to provide a solution which not only utilizes waste packaging Pinaceae wood for recycling as raw material but also supplies to the market with a green product responding to the durability requirements in fact. Pinaceae wood packaging residues were chemically processed through two stages. The amount of lignin extract from Pinaceae was determined by the method of Tappi 222 om-02 which was significantly influenced by the extraction parameters such as temperature, time and concentration of the treatment solution. Morphological modification of wood materials was analyzed by SEM micrographs. In particular, the mechanical properties of the Epoxy/TPW2 composite green material have been significantly improved with increasing up to 206-540 \% compared to the original Pinaceae wood. The optical properties of the wood have completely changed from opaque pine wood with the optical transmittance of $8 \%$ into transparent composite material with the optical transmittance up to $85 \%$ using UV-vis spectroscopy analysis.
\end{abstract}

\section{Keywords}

green composite, Pinaceae wood, lignin extraction, chemical treatment, transparent

\section{Introduction}

The solid waste pollution is currently a top concern in most countries all over the world. Indeed, the overpopulation leads to increase demand for food and consumer goods causing more waste, mainly domestic waste, agricultural by-products and industrial waste. In the past, there were many research works used the agricultural by-products such as sisal coir fiber [1], banana fiber [2], water hyacinth fiber [3, 4], cashew nut shell [5], leaf fiber [6] and bamboo fiber to reinforce in wood plastic composites based on epoxy resin [7, 8]. There are twin-screw extruders manufactured with screw length (L) at 36D with advanced technology to produce sheets from wood pulp reinforced thermoplastic composite. In which, the thermoplastics are normally high density polyethylene, polypropylene, polyvinyl chloride and even Acrylonitrile Butadiene Styrene. Meanwhile, the types of domestic waste are sorted, mixed with additives and then they are composted in many days to produce fertilizer for the agricultural production. For the industrial solid waste, the recycling has still faced to many difficulties due to the variety of origins, containing many different components included hazards and toxic substances or heavy metals [9-14]. This is a big obstacle for the recycling and use of the industrial solid waste as raw materials for other industries.

Research by Nguyen and Nguyen [13] in 2021 treated kraft paper packaging by-products to manufacture lightweight panels with sandwich core structure, applied in the field of building materials. In addition, there are a lot of Pinaceae wood packaging that is discarded piled up or used as firewood with low economic value in factories. The wooden packages mainly contain machines or spare parts in industrial production. Therefore, it is necessary to have a solution for utilization this raw material as a raw material for other industries. 
The wood and agricultural by-products must be treated before used as raw materials for other industries. Vaccarino et al. [15] reported that the highest amount of lignin was extracted in solution of $\mathrm{NaOH}$ and $\mathrm{Na}_{2} \mathrm{CO}_{3}$ at $60{ }^{\circ} \mathrm{C}$. Silverstein et al. [16] studied the effect of sulfuric acid, sodium hydroxide, hydrogen peroxide, ozone on cotton fibers. In which, the highest value of lignin extraction at $65 \%$ was in the solution of $2 \% \mathrm{NaOH}$ for 90 minutes at $120{ }^{\circ} \mathrm{C}$. Zhu et al. [17] used sodium chlorite solution to extract lignin and the lignin content was drastically reduced with less than $3 \%$ remaining in the samples. The use of chemical solutions to extract the lignin from Pinaceae was first studied by Fink [18] in 1992. According to the study, the combination of polymer and reinforcing materials have the same refraction index at 1.56 increased the light transmittance through the material. Li et al. [19] developed the above method to remove the lignin in chip wood with a thickness less than $1 \mathrm{~cm}$, and then they were combined with some resins such as polystyrene and polymethylmetacrylate. The wood used in the studies had bright white color such as oak, balsa wood, ash wood and others in the form of thin sheets with a thickness of $0.5-3.0 \mathrm{~mm}$.

After treated, the wood-based materials are improved on engineering properties such as strength, toughness, low density and low thermal conductivity [20, 21]. According to Li et al. [22] and Wang et al. [23], the wood-based materials can be used for insulating and cooling in buildings, producing Perovskite solar cells for saving energy [10]. According to Müller et al. [24], the absorption of light is strongly related to the chemical composition of the wood. In which, the lignin is able to absorb about $80-95 \%$ of light transmitted through the wood. Therefore, when the light absorption of the wood or wood-based materials is rocketly reduced, they will become transparent. This can be conducted by deigninfication or neutralization of pigments (chromophores) in the lignin [25, 26].

This study utilized the thin Pinaceae wood chips from waste wood packaging to conduct the lignin treatment and then produce green composite materials with many outstanding advantages on engineering properties compared to the original Pinaceae wood.

\section{Materials and methodology}

\subsection{Raw materials}

The wooden packaging was chosen in type of white Pinaceae, popularly grown in Canada. The packaging was often used for the packaging of machinery, industrial spare parts or consumer goods as shown in Fig. 1. The Pinaceae wood was sawn into white bars, the wooden surface was naturally without being coated any material. The wood has been hulled and processed for exterior cleaning. In all experiments, the Pinaceae samples were cut into thin sheets with a thickness of $2.0 \mathrm{~mm}$.

\subsection{The chemical treatment of Pinaceae wood}

The samples of white Pinaceae wood were cut into squares of $30 \pm 2 \mathrm{~mm}$ with a thickness of $2.0 \pm 0.1 \mathrm{~mm}$. The lignin in Pinaceae wood was treated with a mixture of $\mathrm{NaOH}$ and $\mathrm{Na}_{2} \mathrm{SO}_{3}$ solutions. In which, the $\mathrm{Na}_{2} \mathrm{SO}_{3}$ concentration was fixed at $0.4 \mathrm{M}$ and the $\mathrm{NaOH}$ concentration was changed in the range of 2.0-3.0 M. The extraction temperature was carried out from $30-80{ }^{\circ} \mathrm{C}$ and the treated time was from 1-7 hours. The color changes of the lignin extract were observed and calculated the extracted lignin content. The Pinaceae wood samples were then washed several times with hot water and neutralized with acetic acid. The samples ware further bleached with solution of 2.5 $\mathrm{M} \mathrm{H}_{2} \mathrm{O}_{2}$ for 1-7 hours with a temperature of about $50{ }^{\circ} \mathrm{C}$, washed again and dried to a constant volume.

The experiments were conducted in the temperature conditions of $23{ }^{\circ} \mathrm{C}$, relative humidity of $80 \%$ at the Material Technology Laboratory, Ho Chi Minh City University of Food Industry. The experimental processes are shown in Fig. 2.

\subsection{Method of calculation for the lignin content}

The method of TAPPI 222 om-02 [27] was used to calculate the lignin content in Pinaceae wood. The Pinaceae wood samples were crushed into powder and put in beaker containing $15 \mathrm{~mL}$ of $72 \%$ sulfuric acid. The mixture was continuously stirred and the beaker was kept in the water bath at $20 \pm 1{ }^{\circ} \mathrm{C}$ for 2 hours. Water was added from 300

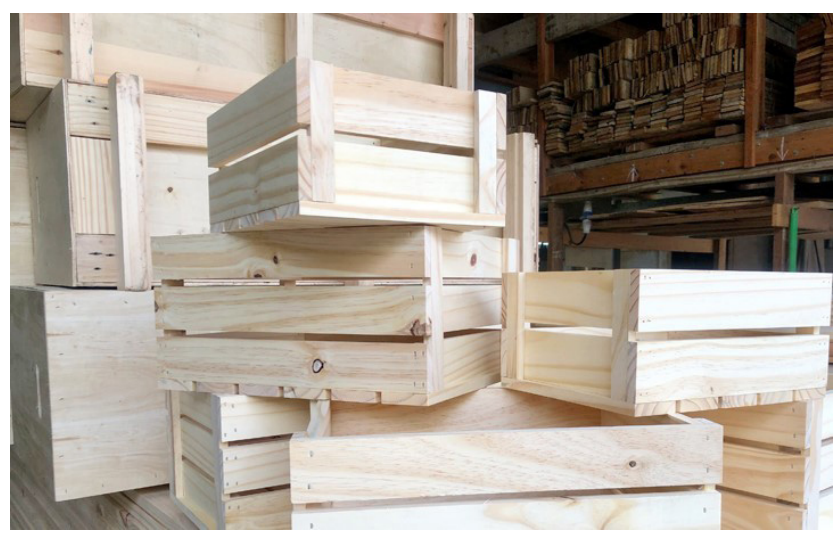

Fig. 1 Pinaceae wood packaging for containing cargo 


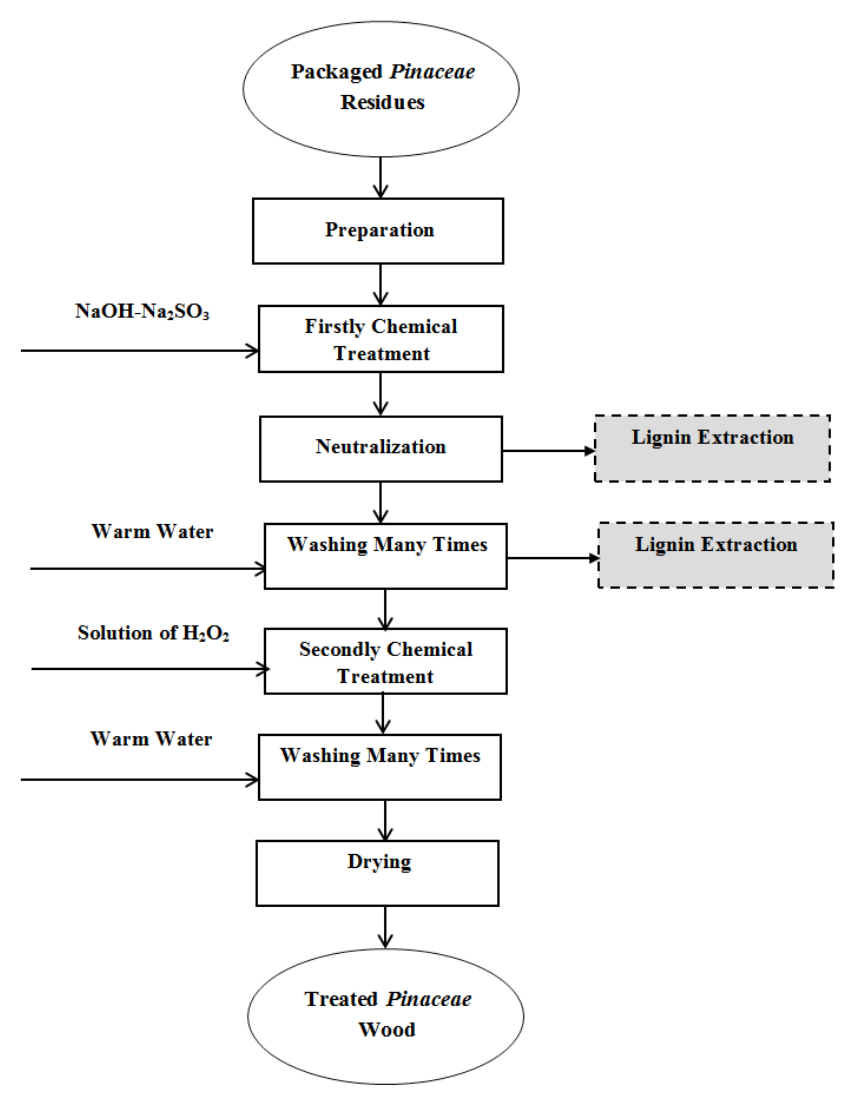

Fig. 2 The chemical treatment processes for the Pinaceae wood packaging residues

to $400 \mathrm{~mL}$ in beaker to rinse and dilute so that the concentration of sulfuric acid in solution was at $3 \%$. The solution was boiled for 4 hours, and then the lignin was settled to the bottom of the flask for 12 hours. The precipitate was filtered and dried at $105 \pm 3{ }^{\circ} \mathrm{C}$ to constant mass.

\subsection{Fabrication of green composite material based on epoxy reinforced Pinaceae wood residues}

An epoxy resin of EPD 3120 pre-polymer was mixed with EPC 3809 hardening agent (Nan Ya Plastics Corporation, Taiwan). The reinforcement materials for the composite were samples of TPW2 sample (chemically treated Pinaceae wood) and UPW (untreated Pinaceae wood) with a thickness of $2.0 \pm 0.1 \mathrm{~mm}$. The Pinaceae wood samples were submerged in epoxy mixture for 30 minutes to have enough time for epoxy mixture to penetrate inside the wood samples. The composite samples were put in an oven with convection air and dried according to the processing parameters of $90^{\circ} \mathrm{C}$ for 2 hours, $120^{\circ} \mathrm{C}$ for 1 hour and continued at $140{ }^{\circ} \mathrm{C}$ for 1 hour to harden epoxy completely. And then the samples were cooled in a desiccator (containing silica gel) for 24 hours to stabilize the dimensions and durability. Finally, the samples were cut into the specimens according to mechanical measurement standards.

\subsection{Microstructural characteristics of Pinaceae wood} and the green composite

Morphology of the Pinaceae wood samples before and after chemical treatment was characterized using Scanning Electron Microscope (SEM) of Hitachi S-4800 (Japan) at the Institute of Nanotechnology - Vietnam National University of Ho Chi Minh City.

\subsection{Analysis of optical transmission of the Pinaceae wood and the green composite materials}

The analytical process was carried out according to "ASTM D1003-13 Standard Test Method for Haze and Luminous Transmittance of Transparent Plastics" [28] standard measuring method for turbidity and optical transmittance of transparent resin - using UV-Vis spectrophotometer (UV-1800 Series, Shimadzu, Japan) to measure optical transmission (Transmittance). A very high intensity light source was used with the spectral region stretches from 190-1100 $\mathrm{nm}$.

\subsection{Evaluation on mechanical strength of the Pinaceae} wood and the green composite materials

The compressive strength was tested according to ASTM D695-15 [29] standard using device of LLOYD LR $30 \mathrm{~K}$ at the Mechanical Measurement Laboratory of the Material Research Center, Ho Chi Minh City University of Technology. The samples were prepared in sizes of ASTM standards D695 with length $(l) \times$ width $(b) \times$ height $(h)$ at $20 \times 20 \times 12 \mathrm{~mm}$, respectively. It is noted that the compression speed was at $1.3 \mathrm{~mm}$ per minute.

The flexural strength of samples was tested according to ASTM D790-17 [30]. This method allows the determination of the flexural properties of reinforced or non-reinforced resins including high-modulus composites. The sample was put on two supports, the load was applied in the center of the sample until the specimens were broken. The bending velocity was of $1.5 \mathrm{~mm}$ per minute and the distance between the two supports was at $60 \mathrm{~mm}$.

\section{Results and discussion}

3.1 Effects of the processing parameters to changes of the extracted lignin content and the Pinaceae wood 3.1.1 Effects of $\mathrm{NaOH}$ concentration on the extracted lignin content

The mixtures of $\mathrm{NaOH}$ and $\mathrm{Na}_{2} \mathrm{SO}_{3}$ solution were used to extract lignin from Pinaceae wood samples with a fixed concentration of $\mathrm{Na}_{2} \mathrm{SO}_{3}$ solution at $0.4 \mathrm{M}$, the extracted temperature of $60{ }^{\circ} \mathrm{C}$ and the extraction time was at 
5 hours. The concentration of $\mathrm{NaOH}$ solution was changed in the range of 2.0-3.0 M. The color of extracted lignin solutions (color bar chart) and the extracted lignin content (line graph) are shown in Fig. 3.

The changes of lignin content according to $\mathrm{NaOH}$ concentration which divided into three stages:

- Stage (1): concentration of $\mathrm{NaOH}$ solution from 2.0 to $2.3 \mathrm{M}$,

- Stage (2): concentration of $\mathrm{NaOH}$ solution from 2.3 to $2.5 \mathrm{M}$ and

- Stage (3): concentration of $\mathrm{NaOH}$ solution from $2.5-3.0 \mathrm{M}$.

In the first stage (Stage (1)), the extract color had a little change, correspondingly, the lignin content increases slowly from $6.18-8.20 \%$. In this sodium hydroxide concentration range, the lignin content increases linearly with that of $\mathrm{NaOH}$ solution as shown in Fig. 3.

In Stage (2), the concentration of $\mathrm{NaOH}$ changed from 2.3 to $2.5 \mathrm{M}$, the lignin content increases rapidly from $8.20 \%$ to $10.40 \%$ according to the concentration of $\mathrm{NaOH}$ solution. With the concentration of $\mathrm{NaOH} 2.5 \mathrm{M}$ or over, the lignin extract starts to change color clearly as shown in Fig. 3 corresponding to a lignin content of $10.40 \%$.

At Stage (3), with higher concentrations of $\mathrm{NaOH}$ from 2.5-3.0 M, the extracted lignin color changed to dark yellow corresponding to an increase of lignin content from 10.40 to $11.02 \%$. The change of the lignin content is linear according to the concentration of $\mathrm{NaOH}$ solution. However, it increases very slowly compared to the first stage.

It is easy to realize that at the $\mathrm{NaOH}$ concentrations less than $2.5 \mathrm{M}$, the extracted lignin capacity was not high. From Fig. 4, the fracture point appears at $2.5 \mathrm{M} \mathrm{NaOH}$ concentration with the lignin extract starts to change color and the lignin content was extracted quite a lot (over $10.40 \%$ ).

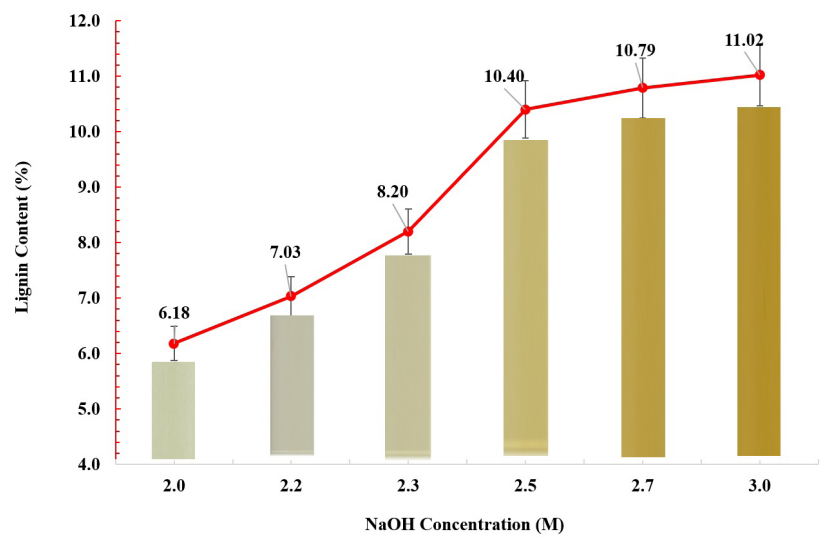

Fig. 3 The changes of lignin content and its extract color in alkaline condition with various concentration

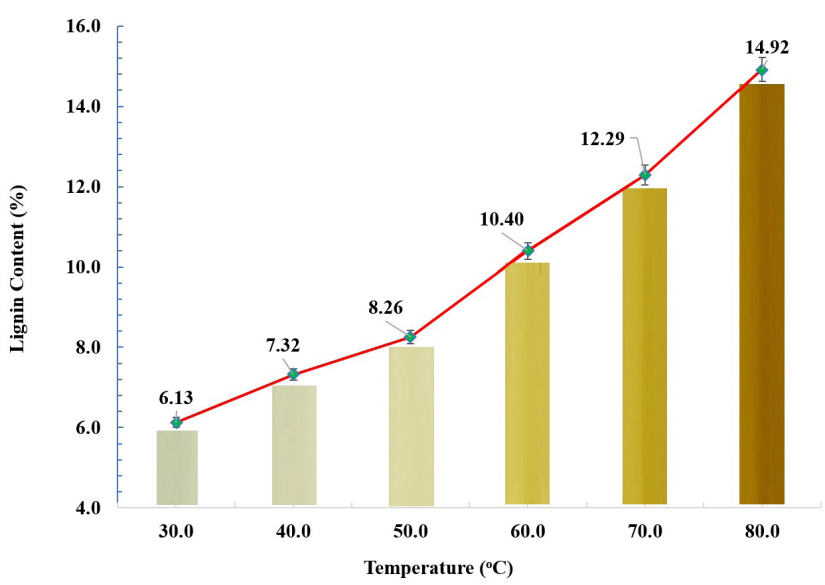

Fig. 4 Effects of the extracted temperature to the lignin content

With the $\mathrm{NaOH}$ concentrations from 2.5-3.0 M, the lignin extraction capacity increased slowly, specifically at the $3.0 \mathrm{M} \mathrm{NaOH}$ concentration, the lignin content was only $11.02 \%$. Therefore, the treatment for lignin in Pinaceae wood was not carried out at $\mathrm{NaOH}$ concentrations over 3.0 M. The concentration of $\mathrm{NaOH}$ at 2.5 M was suitable for pine wood treatment. The experimental results are consistent with previous studies and used for the next experiments $[3,7,8]$.

\subsubsection{Effects of extraction temperature on Lignin content}

The extracted temperature was investigated in the range of $30-80{ }^{\circ} \mathrm{C}$ for 5 hours using a mixture of $\mathrm{NaOH} 2.5 \mathrm{M}$ and $0.4 \mathrm{M} \mathrm{Na}_{2} \mathrm{SO}_{3}$ solution to extract lignin from Pinaceae wood samples. The results of the extracted lignin content (line graph) and its color changes (color bar chart) are presented in Fig. 4.

When the temperature of mixture was increased from 30 to $80^{\circ} \mathrm{C}$, the color of the lignin extraction changed from colorless to brownish yellow corresponding to the higher extracted lignin content. From 30 to $50{ }^{\circ} \mathrm{C}$, the lignin content increases slowly; However, the extracted lignin rate increases faster in the temperature range of $50-80{ }^{\circ} \mathrm{C}$. From $70-80{ }^{\circ} \mathrm{C}$ with higher temperature and long treatment time, the wood samples were deformed and cannot continue for the next experiments. Therefore, the extracted temperature was chosen for the experiments was at $60{ }^{\circ} \mathrm{C}$.

\subsubsection{Effects of the first extracted time using $\mathrm{NaOH}-$ $\mathrm{Na}_{2} \mathrm{SO}_{3}$ solution}

The solution of $\mathrm{NaOH} / \mathrm{Na}_{2} \mathrm{SO}_{3}$ with $\mathrm{NaOH}$ concentration of $2.5 \mathrm{M}$ was used for the experiments at temperature of $60{ }^{\circ} \mathrm{C}$. The extraction time was carried out from 1 to 7 hours with the results as shown in Fig. 5. 


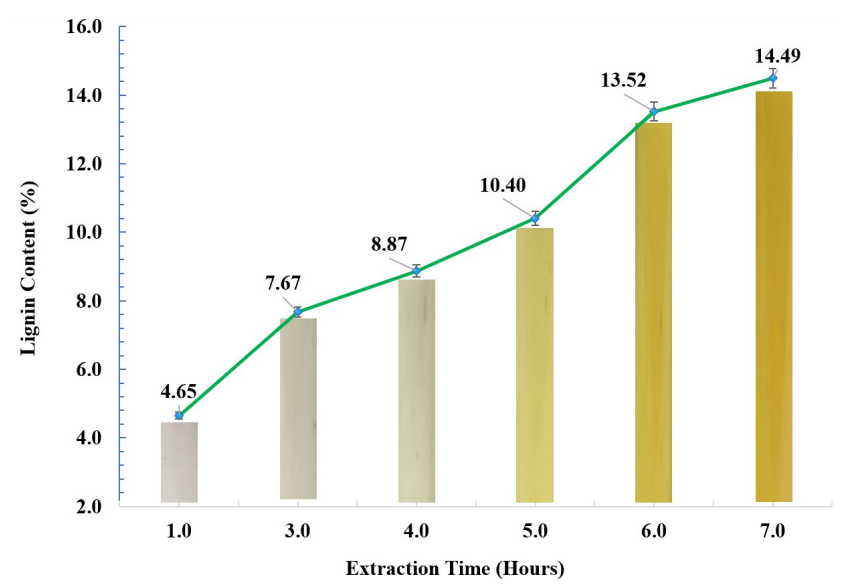

Fig. 5 The changes of lignin content and its extract color during extracted time from 1 to 7 hours using $\mathrm{NaOH}-\mathrm{Na}_{2} \mathrm{SO}_{3}$ solution

The color of lignin extract changed from colorless to dark yellow during the extracted time from 1 to 7 hours as shown in the color bar chart. Thus, the longer the extraction time is, the more the lignin content extracted. Specifically, the lignin content increased from $4.65 \%$ for 1 hour to $14.49 \%$ for 7 hours. It is clear that the extracted lignin content increased more than 3 times.

From the extracted time from 1 to 5 hours, the extract color had a little change, correspondingly, the extracted lignin content increased from $4.65 \%$ to $10.40 \%$ which increased more than 2 times within 4 hours. However, from 5 to 6 hours, the lignin content rose from $10.40 \%$ to $13.52 \%$ higher than 1.3 times within 1 hour). The color of extract also changed clearly from pale yellow to dark yellow. Finally, from 6 to 7 hours, the lignin content changed slowly from $13.52 \%$ to $14.49 \%$ which has an increase of 1.07 times within 1 hour. Thus, the lignin content was quite low with the extracted time less than 5 hours. The lignin content tended to increase slowly with the extracted time higher than 5 hours. Therefore, the extracted time at 5 hours was selected to carry out for the experiments.

\subsubsection{Effects of the second extraction time to the Lignin content using $\mathrm{H}_{2} \mathrm{O}_{2}$ solution}

The first treated Pinaceae wood samples with $\mathrm{NaOH}$ $2.5 \mathrm{M}$ and $\mathrm{Na}_{2} \mathrm{SO}_{3}$ solution at $60{ }^{\circ} \mathrm{C}$ for 5 hours were used to continue the second treatment with $\mathrm{H}_{2} \mathrm{O}_{2}$ solution. Concentration of $\mathrm{H}_{2} \mathrm{O}_{2}$ solution was fixed at $2.5 \mathrm{M}$ during the treated time from 1 to 7 hours. The experimental results for the changes of lignin content (line graph) and the color of Pinaceae wood samples after treatment (color bar chart) are shown in Fig. 6.

After the second treatment with $\mathrm{H}_{2} \mathrm{O}_{2}$ solution from 1 to 7 hours, the extracted lignin content continuously changed from 17.13 to $24.34 \%$ which has an increase of

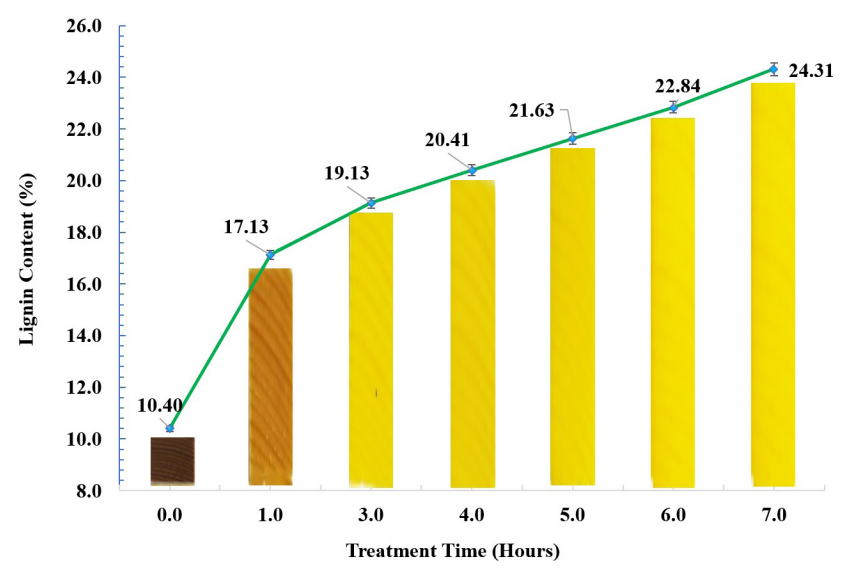

Fig. 6 The changes of the total extracted lignin content and its extract color during 1 to 7 hours using $\mathrm{H}_{2} \mathrm{O}_{2}$ solution

1.5 times as shown in Fig. 7. After treated for 1 hour with $\mathrm{H}_{2} \mathrm{O}_{2}$ solution, the color of Pinaceae wood changed from dark brown to lighter brown with lignin content about $17 \%$. After treated for 3 hours with $\mathrm{H}_{2} \mathrm{O}_{2}$ solution, the brown color of the wood sample disappeared to change yellow. With treatment for 5 hours in $\mathrm{H}_{2} \mathrm{O}_{2}$ solution, the samples had a bright yellow color corresponding to the extracted lignin content at $21.63 \%$ calculated for the total of 2-time treatments. For the treated time over 5 hours, the extracted lignin content increased rapidly reaching to $24.31 \%$. Because the lignin content extracted is very high and quite close to the content of lignin in the Pinaceae wood. Therefore, the treatment time in $\mathrm{H}_{2} \mathrm{O}_{2}$ solution should be at 5 hours. In this treated condition, the Pinaceae wood samples had bright color and the extracted lignin content is not too high to affect the structure and durability of the Pinaceae wood.

\subsubsection{The changes of Pinaceae wood color after secondly treatment}

The changes of Pinaceae wood color were observed according to the first treatment time $\left(t_{1}\right)$ with the mixture of $\mathrm{NaOH} / \mathrm{Na}_{2} \mathrm{SO}_{3}$ solution for 1 to 13 hours and the second treatment time $\left(t_{2}\right)$ using $\mathrm{H}_{2} \mathrm{O}_{2}$ solution with changes in the range of 1 to 5 hours. The results were simultaneously recorded with 2 parameters of $t_{1}$ and $t_{2}$ as shown in Table 1 .

The longer treatment time in the solution of $\mathrm{NaOH} / \mathrm{Na}_{2} \mathrm{SO}_{3}$ mixture is, the more the amount of extracted lignin is. This caused correspondingly the color of the Pinaceae wood changed from yellow brown to black after 13 hours due to the dissolution of lignin, tannins and pectin in extracted solution. Therefore, it is necessary to use $\mathrm{H}_{2} \mathrm{O}_{2}$ solution to treat wood color. The experimental results showed that the color of the Pinaceae wood was gradually lighter after bleaching and cleaning. 


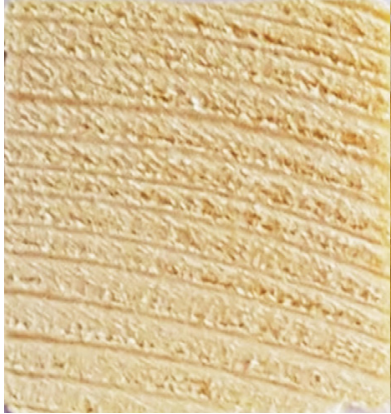

(a)

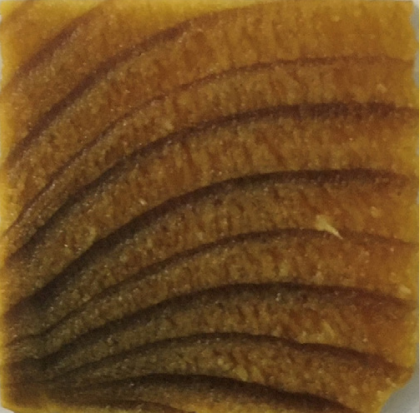

(b)

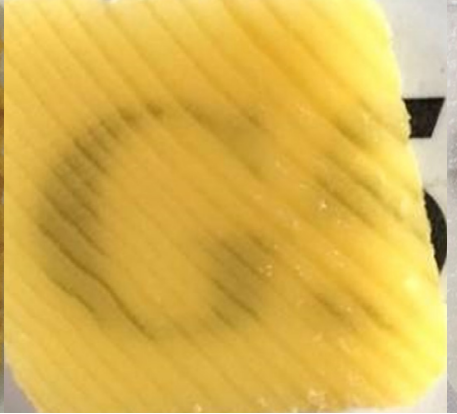

(c)

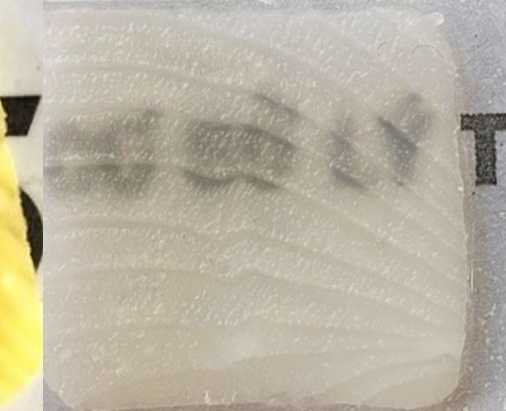

(d)

Fig. 7 The color of Pinaceae wood and green composite materials reinforced Pinaceae wood: (a) The initial white Pinaceae wood without treatment (UPW); (b) The Pinaceae wood after the first treatment using $\mathrm{NaOH}-\mathrm{Na}_{2} \mathrm{SO}_{3}$ solution (TPW1); (c) The Pinaceae wood after the second treatment with $\mathrm{H}_{2} \mathrm{O}_{2}$ solution (TPW2); and (d) The green composite materials based on Epoxy/TPW2

Table 1 The changes of lignin content and the color of Pinaceae wood samples during the treated time from 1 to 7 hours using $\mathrm{H}_{2} \mathrm{O}_{2}$ solution

\begin{tabular}{|c|c|c|c|c|c|c|c|}
\hline \multirow{2}{*}{\multicolumn{2}{|c|}{$\begin{array}{l}\text { The Color of Pinaceae Wood after the First Treatment } \\
\text { with Time } t_{1} \text { (hours) }\end{array}$}} & \multicolumn{6}{|c|}{$t_{1}$ (hours) } \\
\hline & & 3 & 5 & 7 & 9 & 11 & 13 \\
\hline \multirow{5}{*}{$\begin{array}{l}\text { The Color of Pinaceae Wood after the } \\
\text { Second Treatment Time } t_{2} \text { (hours) }\end{array}$} & 1 & & & & & & \\
\hline & 2 & & & & & & \\
\hline & 3 & & & & & & \\
\hline & 4 & & & & & & \\
\hline & 5 & & & & & & \\
\hline Lignin content (\%) & & 17.13 & 19.13 & 20.41 & 23.12 & 24.15 & 25.01 \\
\hline
\end{tabular}

Table 1 shows that there are 2 samples treated in conditions of $t_{1}=7$ hours; $t_{2}=5$ hours and $t_{1}=9$ hours; $t_{2}=4$ hours which are bright and uniform color, no wood grain and transparency. It is noted that $t_{1}$ is the treatment time with solution of $\mathrm{NaOH}$ and $\mathrm{Na}_{2} \mathrm{SO}_{3}$ and $t_{2}$ is the treatment time with $\mathrm{H}_{2} \mathrm{O}_{2}$ solution.

\subsubsection{Effects of the treatment times to changes of the Pinaceae wood using $\mathrm{H}_{2} \mathrm{O}_{2}$ solution}

The first treated Pinaceae wood samples with $\mathrm{NaOH}$ and $\mathrm{Na}_{2} \mathrm{SO}_{3}$ solution at $60{ }^{\circ} \mathrm{C}$ for 5 hours $(\mathrm{NaOH} 2.5 \mathrm{M}$ solution) were used to continue for the second treatment with $\mathrm{H}_{2} \mathrm{O}_{2}$ solution. The samples were treated with $2.5 \mathrm{M} \mathrm{H}_{2} \mathrm{O}_{2}$ solution with the number of treatments from 1 to 5 times for the purpose of wood whitening. The experimental results are shown in Table 2.
Table 2 The color changes of Pinaceae wood with the number of treatments using $\mathrm{H}_{2} \mathrm{O}_{2}$ solution

\begin{tabular}{lcccccc}
\hline Number of Treatment & 1 & 2 & 3 & 4 & 5 \\
\hline $\begin{array}{l}\text { The Color of } \\
\text { Pinaceae Wood after }\end{array}$ & & & & & & \\
$\begin{array}{l}\text { Treatment } \\
\text { Lignin Content (\%) }\end{array}$ & 19.13 & 21.24 & 21.32 & 21.53 & 21.92 \\
\hline
\end{tabular}

Initially, the Pinaceae wood has ivory-white with several light brown streaks. The wood is completely opaque and the light cannot be transmitted it as shown in Fig. 7 (a). After treatment with the solution of $\mathrm{NaOH}$ and $\mathrm{Na}_{2} \mathrm{SO}_{3}$ at $60{ }^{\circ} \mathrm{C}$, the compounds such as lignin, pectin, tannins and tree sap were separated and dissolved in the solution causing the wood color changed into dark brown as shown in Fig. 7 (b). The wood samples were continuously secondly treated with $\mathrm{H}_{2} \mathrm{O}_{2}$ solution which has light color with 
fading of the wood grain and the wood color becomes homogeneous as shown in Fig. 7 (c).

Table 2 shows that the content of extracted lignin using $\mathrm{H}_{2} \mathrm{O}_{2}$ solution after the first treatment was at $19.13 \%$, the second treatment was at $21.24 \%$ and others. Finally, the extracted lignin content reached to $21.92 \%$ after treated for 5 times with the solution of $\mathrm{H}_{2} \mathrm{O}_{2}$. It is noted that the extracted lignin content only had a little change (from 21.24 to $21.92 \%$ ) with number of treatments increased from 2 to 5 times. However, the color of Pinaceae wood clearly changed from dark brown with wood grain to bright and uniform color without wood grain and transparency. After combined with transparent and colorless epoxy resin, the green composite materials were fabricated using the epoxy resin reinforced with TPW2 which have bright color with the blurred wood grain and transparent. In particular, the Epoxy/TPW2 green composite sample is almost transparent allowing light to penetrate easily as presented in Fig. 7 (d).

\subsubsection{The changes of Pinaceae wood weight after chemical treatment}

According to Pettersen [31], the content of lignin in white Pinaceae wood is about $27 \%$ in weight of the wood. The experimental results in Table 1 show that after the first treatment for 13 hours with solution of $\mathrm{NaOH}$ and $\mathrm{Na}_{2} \mathrm{SO}_{3}$ and the second treatment for 2 hours, the extracted lignin content was at $25.01 \%$. Or after the first treatment for 11 hours with solution of $\mathrm{NaOH}$ and $\mathrm{Na}_{2} \mathrm{SO}_{3}$ and the second treatment for 3 hours with $\mathrm{H}_{2} \mathrm{O}_{2}$ solution, the extracted lignin content was at $24.15 \%$. The samples of Pinaceae wood were extract a part of lignin and some un-cellulosic compounds such as pectin, tannins and sap. Because the lignin is a biopolymer with a role in binding the hemicelluloses and cellulose walls in the wood. If the lignin is extracted too much, it will affect the properties of composite products [32]. The content of lignin remaining in Pinaceae wood after treatment is about $2 \%$ which are consistent with the study of Li et al. [20, 22]. In these studies, the residual lignin content after treatment was less than $3 \%$. Therefore, after 2 times of chemical treatment, the lignin content was extracted about $25 \%$. This proves that the volume of Pinaceae wood has been significantly reduced to $25 \%$ less than that of initial wood (UPW) after treatment.

\subsection{Microstructure and morphologies of the materials}

There were 3 materials used to observe the microstructure and morphologies included UPW, TPW2, and composite based Epoxy/TPW2. Fig. 8 (a) and (b) shows that the untreated Pinaceae wood (UPW) has smooth fiber surfaces because the fibers were covered with initial insoluble mainly compounds such as lignin, pectin, tannins, insoluble wax compounds. In addition, the compounds of lignin and binders made closely bonds with cellulose and hemicellulose in the microstructure of the Pinaceae wood. Therefore, it is difficult to observe the fiber surface as well as the arrangement of structure among the fibers in the original Pinaceae wood sample.

For the secondly treated Pinaceae wood (TPW2), Fig. 8 (c) shows that the surface of TPW2 fibers became rougher than UPW, no longer as smooth as the original UPW sample. Because a part of lignin and the above uncellulose components had been extracted and separated from the Pinaceae wood fibers in high alkaline condition of $\mathrm{NaOH}$ and $\mathrm{Na}_{2} \mathrm{SO}_{3}$ solution. These experimental results are consistent with the previous research of Nguyen and Nguyen [3] when treatment for hyacinth fibers in high alkaline solution.

In addition, the arrangement of the fibers in Pinaceae wood was also changed due to the loss of lignin not only on the fiber surfaces but also among the wood fibers. This leads to the expansion of micropores among the Pinaceae wood fibers due to the lignin loss in the alkaline solution as shown in Fig. 8 (d). These proves that the Pinaceae wood treatment had changed the microstructure and morphologies of the samples.

During the fabrication of modified Pinaceae wood reinforcement composite (Epoxy/TPW2), the Pinaceae wood was impregnated with epoxy resin. Therefore, the epoxy resin not only completely covered the surface of Pinaceae wood fibers but also were permeable the inner structures of fibers. Therefore, it is difficult to clearly observe the surface structure of the wood fibers as shown in Fig. 8 (e). The micropores among the Pinaceae wood fibers were also filled with the epoxy resin blocks causing difficult to observe the structural arrangement of the fibers inside the composite as shown in Fig. 8 (f). The experimental results are consistent with previous studies of Nguyen and Nguyen [3] when treatment of water hyacinth and bamboo fibers in high alkaline condition to reinforce composite materials.

\subsection{Optical transmission of the materials using UV-Vis spectroscopy with transparent characteristic of the composite based Epoxy/TPW2}

The samples of UPW 2 mm, Epoxy/TPW2 2 mm, Epoxy/ TPW2 $5 \mathrm{~mm}$, and Pure Epoxy $2 \mathrm{~mm}$ were used to test for optical transmission. Fig. 7 (a) shows that the original untreated Pinaceae wood (UPW sample) has a light brown 


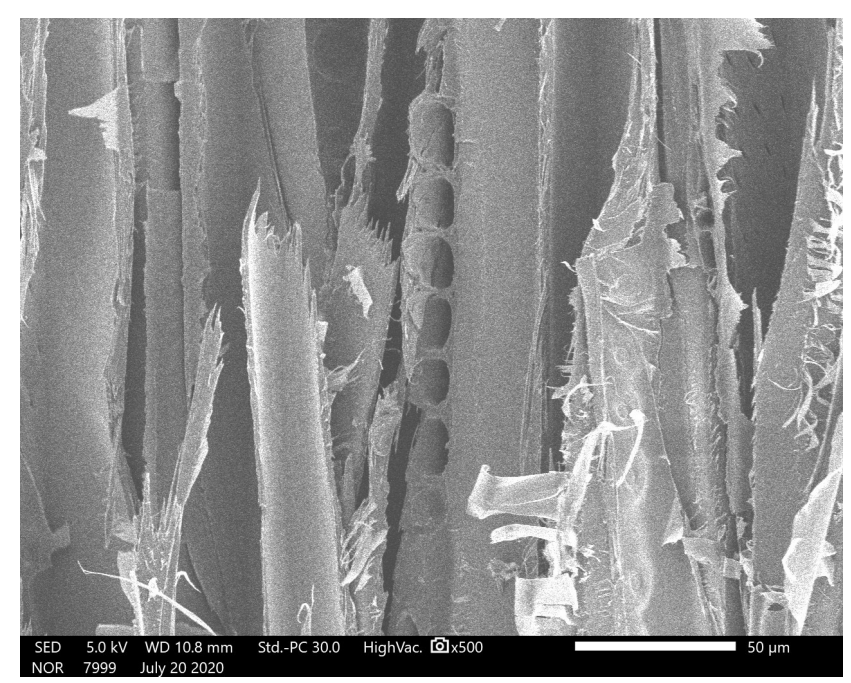

(a)

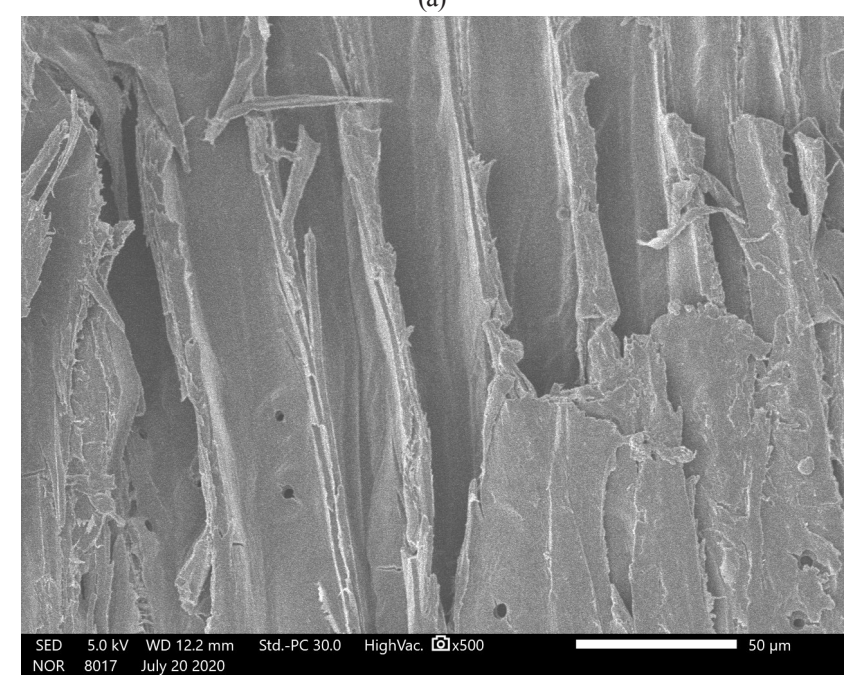

(c)

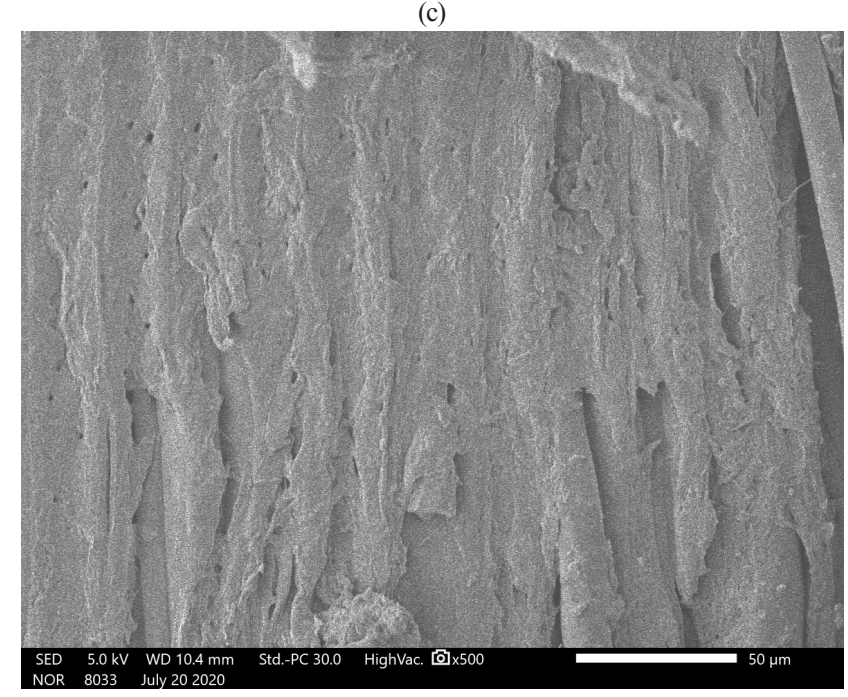

(e)

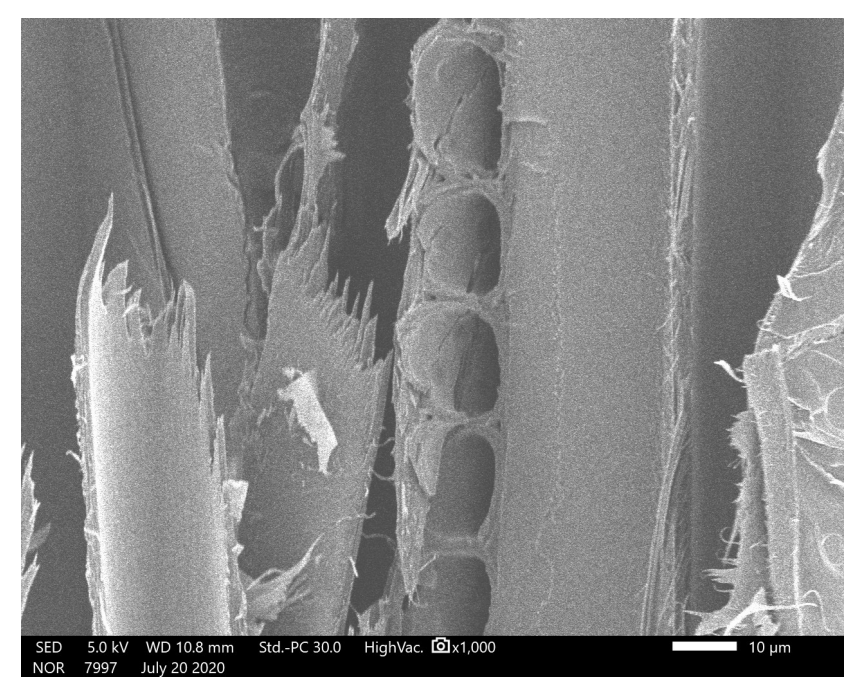

(b)

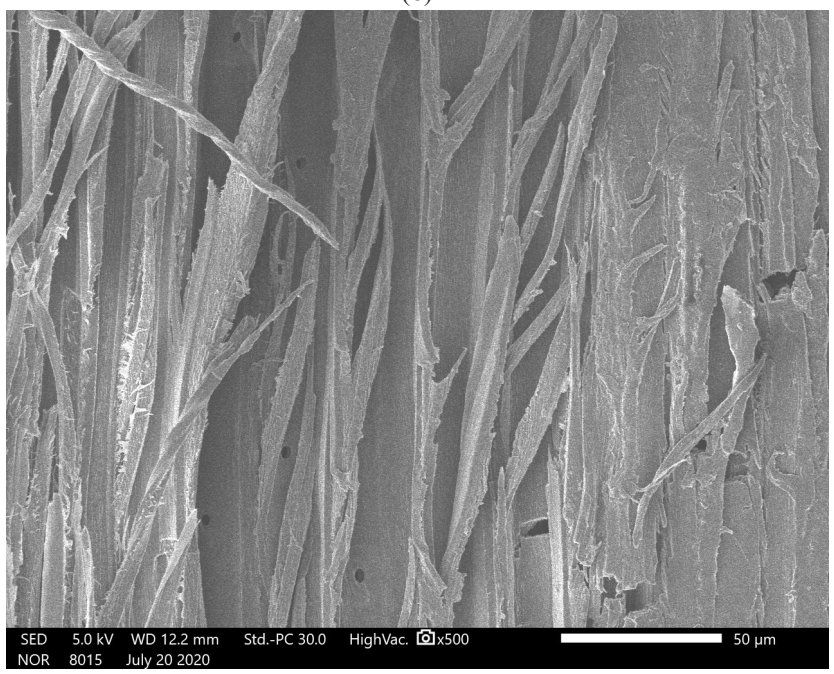

(d)

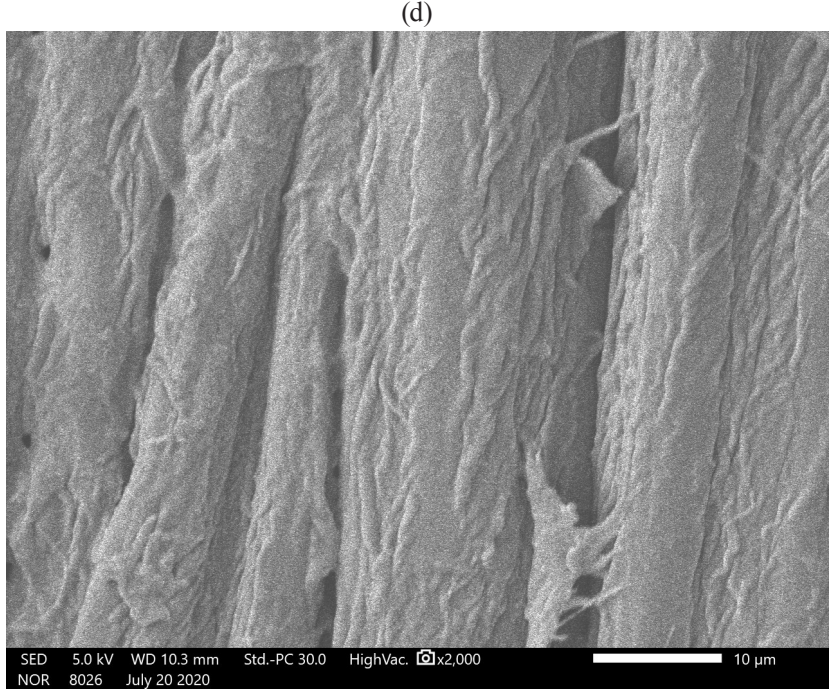

(f)

Fig. 8 The microstructure and morphologies of the Pinaceae wood fiber surfaces with samples of UPW, TPW2, and Epoxy/TPW2: (a) Initial UPW at magnification of 500×; (b) Initial UPW at magnification of 1000×; (c) TPW2 at magnification of 500×; (d) TPW2 at magnification of 1000×;

(e) Epoxy/TPW2 at magnification of 500×; and (f) Epoxy/TPW2 at magnification of 1000× 
color due to the presence of some light-absorbing components such as lignin, chlorophyll and tannins. In addition, the UPW sample is completely opaque and the light cannot be transmitted. The analysis results by UV-Vis spectrophotometer showed that the optical transmittance of UPW samples is very low only at $8 \%$ as shown in Fig. 9 which is consistent with research by Müller et al. [24].

Fig. 7 (d) shows that the color of the wood lightens due to the chemical treatment, most of the lignin, chlorophyll and tannins have been dissolved and extracted. In combination with a transparent epoxy resin substrate, the green composite of Epoxy/TPW2 has very high transparency compared to the untreated Pinaceae wood sample. The UV-vis spectroscopy shows that the optical transmittance of the Epoxy/ TPW2 sample increased rocketly up to $85 \%$, completely consistent with the loss of lignin content in raw material. It is noted that the transparency of the pure epoxy resin is at $95 \%$ (transparent form) and consistent with previous studies $[12,33]$. It is noted that the sample of Epoxy/TPW2 $2 \mathrm{~mm}$ with $2 \mathrm{~mm}$ thickness had transparency at $85 \%$ and it is higher than that of sample Epoxy/TPW2 $5 \mathrm{~mm}$ with $5 \mathrm{~mm}$ thickness with transparency at $42 \%$.

\subsection{Effects of the treatment processes to mechanical} strength of the green composite based epoxy reinforced the Pinaceae wood

\subsubsection{Evaluation on flexural strength of the materials}

There are 4 materials tested the mechanical strength including UPW (untreated Pinaceae wood), TPW2 (treated Pinaceae wood after 2 treated stages), Epoxy/
UPW (the composite based epoxy reinforced untreated Pinaceae wood), and Epoxy/TPW2 (the composite based epoxy reinforced treated Pinaceae wood after 2 treated stages). The samples were prepared with the thickness at $5.0 \pm 0.1 \mathrm{~mm}$ according to ASTM D790-17 [30]. The values of flexural strength and flexural modulus are shown in Fig. 10 and Table 3.

Fig. 10 show that the sample of TPW has a flexural strength of $12.11 \mathrm{MPa}$, which is lower than that of the original UPW sample at $14.63 \mathrm{MPa}$. Thus, after treatment, TPW sample was reduced $17 \%$ values of flexural strength compared with UPW sample. This shows that the extraction of lignin from the Pinaceae wood decreased the flexural strength of the material. Because the lignin is a cross-linked biopolymer roling as a binder among cellulose, hemicelluloses and other components in the natural wood structures. The chemical solutions broke the bonding partials of the above compounds leading to a decrease in the mechanical properties of the Pinaceae wood samples.

The epoxy-based composite materials reinforced UPW and TPW2 have high values of flexural strength at 30.15 MPa and 65.20 MPa, respectively. Specifically, the composite sample of Epoxy/UPW increased $206 \%$ compared with the flexural strength of UPW. The flexural strength of Epoxy/TPW2 composite sample reached to 65.20 MPa with an increase of $540 \%$ compared to the flexural strength of the TPW sample at $12.11 \mathrm{MPa}$. The experimental results show a marked improvement in flexural strength when the samples of UPW and TPW2 were used as raw materials to fabricate epoxy-based composites.

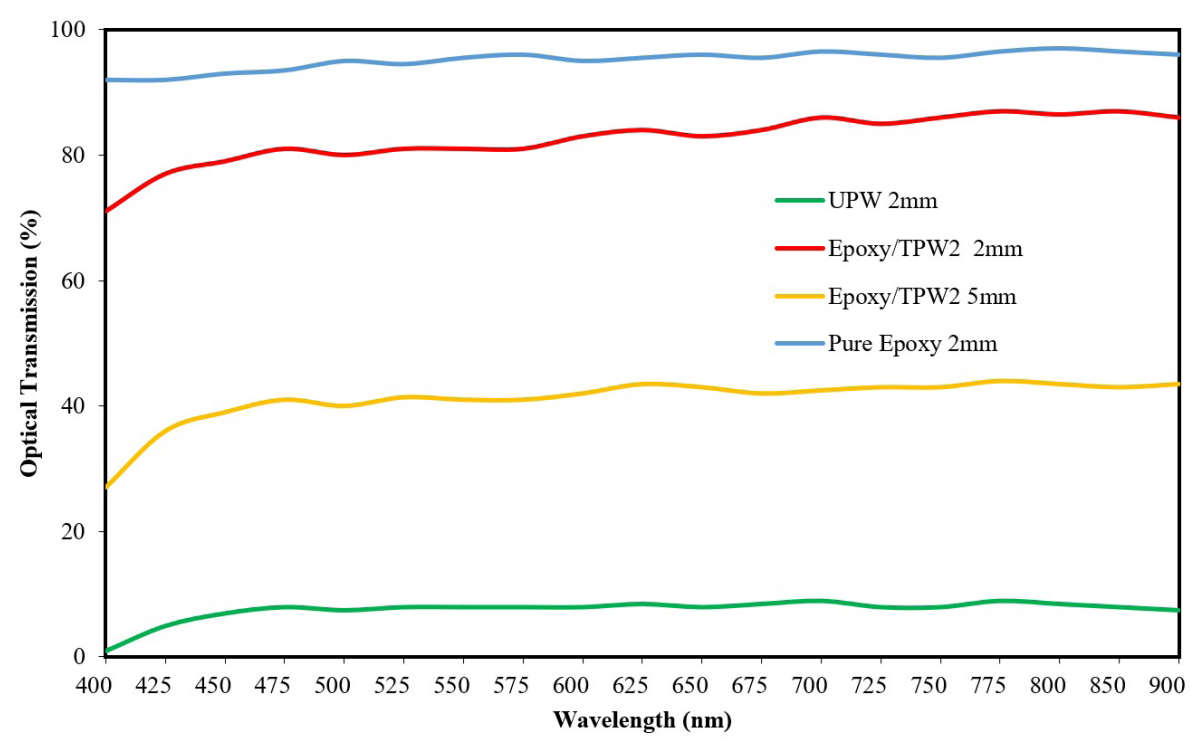

Fig. 9 The optical transmission of samples with various thickness: UPW 2 mm, Epoxy/TPW2 5 mm, Epoxy/TPW2 2 mm, and Pure Epoxy 2 mm 


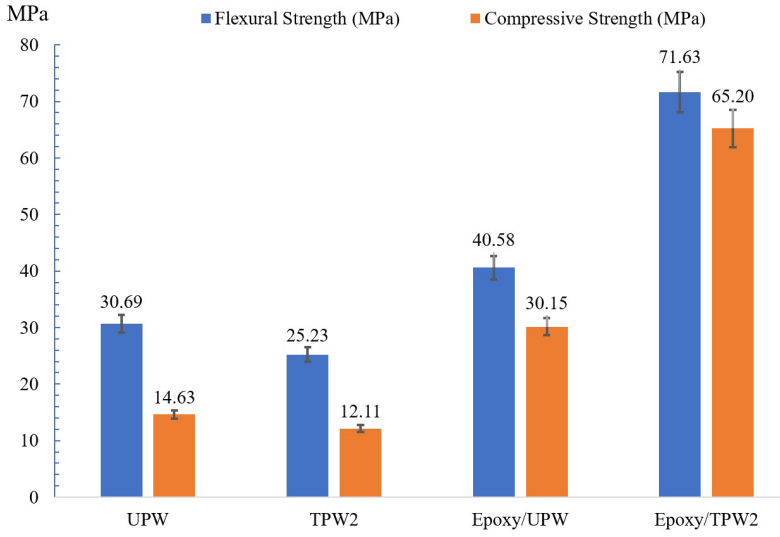

Fig. 10 Improvement on flexural strength of the composite based on epoxy reinforced the treated Pinaceae wood

Table 3 Flexural modulus and compressive modulus of the materials

\begin{tabular}{lcccc}
\hline Modulus & UPW & TPW2 & $\begin{array}{c}\text { Materials } \\
\text { Epoxy/UPW }\end{array}$ & Epoxy/TPW2 \\
\hline $\begin{array}{l}\text { Flexural Modulus } \\
(\mathrm{MPa})\end{array}$ & 150.20 & 112.34 & 458.22 & 1673.85 \\
$\begin{array}{l}\text { Compressive } \\
\text { Modulus (MPa) }\end{array}$ & 320.90 & 276.60 & 382.70 & 424.73 \\
\hline
\end{tabular}

Moreover, the flexural strength of the Epoxy/TPW2 composite reaches to $65.20 \mathrm{MPa}$, which is $216 \%$ higher than that of the Epoxy/UPW composite at $30.15 \mathrm{MPa}$. This result shows a role of the wood chemical treatment in improving flexural strength of the composite materials reinforced the wood.

The results are suitable to the studies of Faruk et al. [34] and Zhang et al. [35] on the strength improvement of composite reinforced with the treated bamboo fibers or the study of Nguyen and Nguyen [3] on the composite reinforced the treated water hyacinth and the treated bamboo $[7,8]$. This confirms the important role of Pinaceae wood treatment to improve the flexural strength of the composite.

\subsubsection{Evaluation on compressive strength of the materials}

The compressive strength and compressive modulus of the materials of UPW, TPW2, Epoxy/UPW, and Epoxy/ TPW2 were tested according to ASTM D695-15 [29] with the results as shown in Table 3 and Fig. 10.

Fig. 10 shows that the compressive strength of the sample of UPW is at $30.69 \mathrm{MPa}$, which is $17.79 \%$ higher than that of the sample of TPW2 at $25.23 \mathrm{MPa}$. Thus, after the chemical treatment, the Pinaceae wood was reduced the compressive strength due to partial extraction of lignin as similarly to the flexural strength. The composites of Epoxy/UPW and Epoxy/TPW2 increased dramatically the compressive strength compared to that of the initial samples of UPW and TPW2. In which, the compressive strength of Epoxy/UPW composite sample increased to $40.58 \mathrm{MPa}$. Similarly, the compressive strength of Epoxy/TPW2 composite sample reached to $71.62 \mathrm{MPa}$. Thus, there were rocketly changes up to $234 \%$ in the compressive strength of composite materials from $30.60 \mathrm{MPa}$ (Epoxy/UPW) to $71.62 \mathrm{MPa}$ (Epoxy/TPW2). The increase in compressive strength indicates that the successful treatment of Pinaceae wood has rocketly increased the compressive strength of the composite-based materials.

The values of compressive strength in this study are consistent with the previous studies for improvement on mechanical strength of the composites reinforced by the recycling materials with chemical treatment. The investigations with the same results included the studies of Akash et al. [1] on the composite using sisal and coir fiber to reinforce; Nguyen and Nguyen [3] on using bamboo to reinforce the composites; Abdul Motaleb et al. [6], used banana and fiberglass blends; and Naveen Reddy et al. [2] fabricated the composite based on epoxy reinforced pineapple fiber; as well as Do et al. [36], Maisuriya et al. [37], Antov et al. [38, 39] studied on glass fiber, banana, wood fiber, agricultural waste for reinforcing the composite-based materials.

\section{Conclusions}

The Pinaceae wood had a significantly changes on the properties of physical, chemical, morphologies, microstructure, and UV-vis, and SEM after the chemical treatment. The low alkaline solutions of $\mathrm{NaOH}$ and $\mathrm{Na}_{2} \mathrm{SO}_{3}$ and $\mathrm{H}_{2} \mathrm{O}_{2}$ mainly extracted and separated lignin and pectin and tannin compounds in the Pinaceae wood. The experimental results show that the chemical type, concentration and extraction time had significantly affected on the extracted lignin content. The secondly treated Pinaceae wood (TPW2) was used to reinforce for composite materials based on epoxy resin which improved dramatically on its mechanical properties. In particular, the optical properties of the wood have changed from a completely opaque to an almost transparent after combined with an epoxy resin substrate. The successful recycling of Pinaceae wood packaging waste contributes to the manufacture of green composite materials that are environmentally friendly products as well as reducing input costs due to reusing the wood waste. Further research should be conducted testing different application properties of composite materials such as thermal conductivity, sound insulation, chemical resistance, and others. 


\section{References}

[1] Akash, Sreenivasa Rao, K. V., Venkatesha Gupta, N. S., Arun Kumar, D. S. "Mechanical Properties of Sisal/Coir Fiber Reinforced Hybrid Composites Fabricated by Cold Pressing Method", In: International Conference on Advances in Materials and Manufacturing Applications (IConAMMA-2016), Bangalore, India, 2016, Article number: 012092.

https://doi.org/10.1088/1757-899X/149/1/012092

[2] Naveen Reddy, C., Bhargav, M., Kaviti, A. K. "Mechanical Characterization of Unidirectional Banana-Glass Fiber Reinforced Hybrid Composites", In: Voruganti, H. K., Kumar, K. K., Krishna, P. V., Jin, X. (eds.) Advances in Applied Mechanical Engineering, Springer, Singapore, Republic of Singapore, 2020, pp. 1031-1038.

https://doi.org/10.1007/978-981-15-1201-8_110

[3] Nguyen, T. H., Nguyen, H. B. T. "Eco-friendly Materials of Polymer Composites Based on Water Hyacinth Fibers/Roving", Journal of Polymer \& Composites, 8(3), pp. 62-69, 2020. https://doi.org/10.37591/jopc.v8i3.4350

[4] Ortenero, J. R., Tumolva, T. P., Kubouchi, M. "Water Hyacinth Fiber-Reinforced Green Composites", In: The $7^{\text {th }}$ International Workshop on Green Composites (IWGC-7), Hamamatsu, Japan, 2012, pp. 28-30.

[5] Do, Q. M., Huynh, N. M., Nguyen, V. U. N., Nguyen, N. T. H., Kieu, D. T. K., Pham, T. K., Nguyen, H. T. "The Influence of Composition of Raw Materials on Formation of Phenolic Resin from Cashew Nut Shell Waste (CNSW)", Defect and Diffusion Forum, 394, pp. 103-108, 2019.

https://doi.org/10.4028/www.scientific.net/DDF.394.103

[6] Abdul Motaleb, K. Z. M., Shariful Islam, M., Hoque, M. B. "Improvement of Physicomechanical Properties of Pineapple Leaf Fiber Reinforced Composite", International Journal of Biomaterials, 2018, Article ID: 7384360, 2018.

https://doi.org/10.1155/2018/7384360

[7] Nguyen, T. B. H., Nguyen, H. T. "Enhancement for Mechanical Properties of Green Composites Using Treated Yellow Bamboo", Materials Science Forum, 1029, pp. 57-63, 2021.

https://doi.org/10.4028/www.scientific.net/MSF.1029.57

[8] Nguyen, T. B. H. "Microstructural Characteristics and Mechanical Properties of the Green Composites Reinforced Bamboo Optimized the Treated Parameters", Journal of Polymer \& Composites, 9(1), pp. 28-38, 2021.

[9] Nguyen, H. T. "Microstructure Stability and Thermal Resistance of Ash-Based Geopolymer with Sodium Silicate Solution at High Temperature", International Journal of Engineering Research in Africa, 53, pp. 101-111, 2021.

https://doi.org/10.4028/www.scientific.net/JERA.53.101

[10] Papadopoulos, A. N. "Advances in Wood Composites", Polymers, 12(1), Article number: 48, 2020. https://doi.org/10.3390/polym12010048

[11] Nguyen-Thuc, B. H., Maazouz, A. "Elastomer-modified epoxy/ amine systems in resin transfert molding process", Polymer International, 53(5), pp. 591-602, 2004.

https://doi.org/10.1002/pi.1437
[12] Antov, P., Savov, V., Neykov, N. "Sustainable Bio-based Adhesives for Eco-friendly Wood Composites. A Review", Wood Research, 65(1), pp. 51-62, 2020.

https://doi.org/10.37763/wr.1336-4561/65.1.051062

[13] Nguyen, T. B. H., Nguyen, H. T. "Lightweight Panel for Building Construction Based on Honeycomb Paper Composite/CoreFiberglass Composite/Face Materials", Nano Hybrids and Composites, 32, pp. 15-23, 2021. https://doi.org/10.4028/www.scientific.net/NHC.32.15

[14] Nguyen, H. T., Dang, T. P. "Fly Ash-Based Geopolymer: Green Materials in Carbon-Constrained Society", Solid State Phenomena, 321, pp. 65-67, 2021.

https://doi.org/10.4028/www.scientific.net/SSP.321.65

[15] Vaccarino, C., Lo Curto, R. B., Tripodo, M. M., Patané, R., Ragno, A. "Grape marc as a source of feedstuff after chemical treatments and fermentation with fungi", Bioresource Technology, 40(1), pp. 35-41, 1992. https://doi.org/10.1016/0960-8524(92)90116-F

[16] Silverstein, R. A., Chen, Y., Sharma-Shivappa, R. R., Boyette, M. D., Osborne, J. "A comparison of chemical pretreatment methods for improving saccharification of cotton stalks", Bioresource Technology, 98(16), pp. 3000-3011, 2007. http://doi.org/10.1016/j.biortech.2006.10.022

[17] Zhu, M. W., Song, J. W., Li, T., Gong, A., Wang, Y. B., Dai, J. Q., Yao, Y. G., Luo, W., Henderson, D., Hu, L. B. "Highly Anisotropic, Highly Transparent Wood Composites", Advanced Materials, 28(26), pp. 5181-5187, 2016. https://doi.org/10.1002/adma.201600427

[18] Fink, S. "Transparent Wood - A New Approach in the Functional Study of Wood Structure", Holzforschung, 46(5), pp. 403-408, 1992. https://doi.org/10.1515/hfsg.1992.46.5.403

[19] Li, Y. Y., Vasileva, E., Sychugov, I., Popov, S., Berglund, L. "Optically Transparent Wood: Recent Progress, Opportunities, and Challenges", Advanced Optical Materials, 6(14), Article number: $1800059,2018$.

https://doi.org/10.1002/adom.201800059

[20] Li, Y., Fu, Q. L., Yu, S., Yan, M., Berglund, L. "Optically Transparent Wood from a Nanoporous Cellulosic Template: Combining Functional and Structural Performance", Biomacromolecules, 17(4), pp. 1358-1364, 2016.

https://doi.org/10.1021/acs.biomac.6b00145

[21] Lubis, M. A. R., Hong, M.-K., Park, B.-D., Lee, S.-M. "Effects of recycled fiber content on the properties of medium density fiberboard", European Journal of Wood Products, 76, pp. 1515-1526, 2018. https://doi.org/10.1007/s00107-018-1326-8

[22] Li, T., Zhu, M. W., Yang, Z., Song, J. W., Dai, J. Q., Yao, Y. Y., Luo, W., Pastel G., Yang, B., Hu, L. B. "Wood Composite as an Energy Efficient Building Material: Guided Sunlight Transmittance and Effective Thermal Insulation", Advanced Energy Materials, 6(22), Article number: 1601122, 2016. https://doi.org/10.1002/aenm.201601122 
[23] Wang, X., Zhan, T. Y., Liu, Y., Shi, J. T., Pan, B., Zhang, Y. L., Cai, L. P., Shi, S. Q. "Large-Size Transparent Wood for Energy-Saving Building Applications", ChemSusChem, 11(23), pp. 4086-4093, 2018.

https://doi.org/10.1002/cssc.201801826

[24] Müller, U., Rätzsch, M., Schwanninger, M., Steiner, M., Zöbl, H. "Yellowing and IR-changes of spruce wood as result of UV-irradiation", Journal of Photochemistry and Photobiology B: Biology, 69(2), pp. 97-105, 2003.

https://doi.org/10.1016/S1011-1344(02)00412-8

[25] Li, Y. Y., Fu, Q. L., Rojas, R., Yan, M., Lawoko, M., Berglund, L. "Lignin-Retaining Transparent Wood", ChemSusChem, 10(17), pp. 3445-3451, 2017.

https://doi.org/10.1002/cssc.201701089

[26] Antov, P., Mantanis, G. I., Savov, V. "Development of Wood Composites from Recycled Fibres Bonded with Magnesium Lignosulfonate", Forests, 11(6), Article number: 613, 2020. https://doi.org/10.3390/f11060613

[27] Technical Association of the Pulp and Paper Indutstry (TAPPI) "TAPPI T 222 Acid-insoluble lignin in wood and pulp (Reaffirmation of T 222 om-02)", TAPPI, Norcross, GA, USA, 2006. [online] Available at: https://www.tappi.org/content/SARG/ T222.pdf [Accessed: 08 February 2021]

[28] ASTM International "ASTM D1003-13 Standard Test Method for Haze and Luminous Transmittance of Transparent Plastics", ASTM International, West Conshohocken, PA, USA, 2013. http://doi.org/10.1520/D1003-13

[29] ASTM International "ASTM D695-15 Standard Test Method for Compressive Properties of Rigid Plastics", ASTM International, West Conshohocken, PA, USA, 2015. http://doi.org/10.1520/D0695-15

[30] ASTM International "ASTM D790-17 Standard Test Methods for Flexural Properties of Unreinforced and Reinforced Plastics and Electrical Insulating Materials", ASTM International, West Conshohocken, PA, USA, 2017. http://doi.org/10.1520/D0790-17

[31] Pettersen, R. C. "The Chemical Composition of Wood", In: Rowel, R. (ed.) The Chemistry of Solid Wood, ACS Publications, Washington, DC, USA, pp. 57-126, 1984. http://doi.org/10.1021/ba-1984-0207.ch002
[32] Iravani, S., Varma, R. S. "Greener synthesis of lignin nanoparticles and their applications", Green Chemistry, 22(3), pp. 612-636, 2020. https://doi.org/10.1039/C9GC02835H

[33] Li, Y. Y., Cheng, M., Jungstedt, E., Xu, B., Sun, L. C., Berglund, L. "Optically Transparent Wood Substrate for Perovskite Solar Cells", ACS Sustainable Chemistry \& Engineering, 7(6), pp. 6061-6067, 2019. https://doi.org/10.1021/acssuschemeng.8b06248

[34] Faruk, O., Bledzki, A. K., Fink, H.-P., Sain, M. "Biocomposites reinforced with natural fibers: 2000-2010", Progress in Polymer Science, 37(11), pp. 1552-1596, 2012.

https://doi.org/10.1016/j.progpolymsci.2012.04.003

[35] Zhang, K., Wang, F. X., Liang, W. Y., Wang, Z. Q., Duan, Z. W., Yang, B. "Thermal and Mechanical Properties of Bamboo Fiber Reinforced Epoxy Composites", Polymers, 10(6), Article number: $608,2018$.

https://doi.org/10.3390/polym10060608

[36] Do, Q. M., Nguyen, V. U. N., Nguyen, H. T. "Development of Refractory Synthesized from Waste Ceramic Fiber and Chamotte", Journal of Polymer \& Composites, 8(2), pp. 101-109, 2020. https://doi.org/10.37591/jopc.v8i2.4293

[37] Maisuriya, V., Jain, P. S., Jariwala, H., Badagha, D. G. "Analysis of Unidirectional Aligned Banana and Glass Fibre Reinforced Polyester Composite for Tensile and Flexural Strength", Journal of Polymer \& Composites, 8(2), pp. 49-61, 2020. https://doi.org/10.37591/jopc.v8i2.3936

[38] Antov, P., Jivkov, V., Savov, V., Simeonova, R., Yavorov, N. "Structural Application of Eco-Friendly Composites from Recycled Wood Fibres Bonded with Magnesium Lignosulfonate", Applied Sciences, 10(21), Article number: 7526, 2020. https://doi.org/10.3390/app10217526

[39] Antov, P., Savov, V., Neykov, N. "Utilization of Agricultural Waste and Wood Industry Residues in the Production of Natural Fiberreinforced Composites Materials", International Journal - Wood, Design \& Technology, 6(1), pp. 64-71, 2017. [online] Available at: http://www.fdtme.ukim.edu.mk/en/wood_journal/archive/vol_6_ no1/vol_6_nol_fulltext_9.pdf [Accessed: 11 May 2021] 